\title{
Design of Cusum Scheme for Monitoring Road Accident Fatalities
}

\author{
Kayode Samuel Adekeye ${ }^{1^{*}}$, Omololu Stephen Aluko ${ }^{2}$ \\ ${ }^{1}$ Department of Mathematical Sciences, Redeemer's University, Redemption City, Nigeria \\ ${ }^{2}$ Department of Mathematical Sciences, Federal University of Technology, Akure, Nigeria \\ Email: *samadek_2017@yahoo.co.uk
}

Received December 9, 2011; revised January 12, 2012; accepted January 25, 2012

\begin{abstract}
In recent years, road accident fatalities in Nigeria have continued to be on the increase. Thus, urgent attention is needed to reduce or eliminate road accidents fatalities. To achieve this goal, the cumulative sum (Cusum) control chart scheme was designed for monitoring the road accident fatalities using the recorded occurrence of road accident fatalities in a state in the western part of Nigeria. The designed Cusum detects the period of the years when the highest occurrence of road accident fatalities occurred. These periods were observed to be festive periods such as Christmas, Easter, Eid-elKabir, and Eid-el-Moluod. Therefore, the festive periods of the year should be used as benchmark by road managers as periods where more attention or precaution measure should be put in place on the roads to drastically reduce or eliminate high occurrence of road accident fatalities. The designed Cusum control chart can be adapted for other states in the country and also for the larger society for detecting the periods when the rate of death as a result of road accidents was prevalent.
\end{abstract}

Keywords: Cusum; Fatalities; Monitoring; Prevalent; Road Accident

\section{Introduction}

The problem of deaths and injury as a result of road accidents is now acknowledge to be a global phenomenon with authorities in virtually all countries of the world concerned about the growth in the number of people killed and seriously injured on their roads. Fatality means, a death that is caused in an accident or war or the fact that a particular disease or accident will result in death". In recent years there have been two major studies of causes of death worldwide which have been published in the "Global Burden of Disease" (2008). This publication show that road accidents as a cause of death or disability were by no means insignificant as it is in the ninth place out of a total of over 100 separately identified causes of death [1].

In recent years, road accident fatalities in Nigeria have continued to be on the increase. This study is motivated by recent interest of Nigerian government to minimize the road fatal accidents by $50 \%$ in year 2015 . Thus, urgent attention is needed to be given to our road transportation system in order to reduce or eliminate road accidents fatalities and save lives.

In this paper, our focus is to develop a Cusum control chart that will be able to assist the government to achieve

${ }^{*}$ Corresponding author. the above stated goal. The cumulative sum (Cusum) control chart scheme was designed for monitoring the road accident fatalities using the recorded occurrence of road accident fatalities in a state in the western part of Nigeria. The designed Cusum control chart can be adapted for other states in the country and also for the larger society for detecting the time point (month) of the year when the rate of death as a result of road accidents was prevalent (high occurrence) and the cumulative trend for road accident fatalities so that appropriate actions would be taken to forestall re-occurrence. The designed scheme is expected to serve as a useful tool for road managers in their effort to reduce road accident fatalities.

\section{The Cumulative Sum (Cusum) Control Chart}

A Cumulative Sum (Cusum) control chart is a graphical representation of the trend in the outcome of a series of consecutive procedures performed over time. The Cusum control charts attempt to device a simple procedure that will make use of all available information. The unique and important feature of Cusum is its ability to indicate the trend of deteriorating performance early, prompting preventive and corrective measures. A major advantage of this chart over the ordinary Shewart control chart is 
that it is very effective in detecting relative small shifts. They are more meaningful graphically, as process shifts are often easy to detect and points of change can be easily located [2]. The Cusum control chart is a technique for identifying whether a real problem has arisen and provides a means of estimating the time at which the problem arose. Such information assists in the identification of management changes which might have caused a problem or, alternatively, an improvement, in the attribute of interest. In effect, the Cusum chart functions as a significance test in attempting to distinguish real effects from sampling variance. It was introduced by Page [3], which provided integral equations for approximately the Average Run Length (ARL). Many authors like Lucas [4], Ott et al. [5] and Montgomery [6] have worked on the Cusum control chart. Lucas [4] gave a detailed procedure for designing a counted data Cusum chart based on a poisson counts and implemented it on the occurrence of industrial accidents. Osanaiye and Talabi [7] considered a versatile dimension on the application of Cusum chart in a non-manufacturing sector and implemented it on the cases of diabetes patients. Adekeye [8] applied the concept of cusum control chart to monitor the crime rate in Nigeria. Nix, Rowland and Kemp [9] used Cusum control chart to monitor rare congenital malformations, while Lin and Adams [10] applied Cusum to monitor surgical performance.

Let $X_{1}, X_{2}, \cdots, X_{m}$ be a sequence of observed independent values from a process. Without loss of generality, the in-control process mean is assumed to be zero. The principal feature of the Cusum control chart is that the values of the random variable $X_{i}, i=1,2,3, \cdots, m$ are compared with a pre-determined target or reference value $T$. The cumulative sum of the deviation of the variable $X$ from $T$ is

$$
S_{i}=\left(X_{i}-T\right)+S_{i-1}
$$

It should be noted that when $T$ is unknown, then an estimate of $T$ given by

$$
T=\frac{\sum_{i=1}^{m} X_{i}}{m}
$$

is often used. In the literatures, $S_{0}=0$ is the ideal value used. To determine the trend or process shift, the values of $S_{i}, 1 \leq i \leq m$ are plotted on a chart or presented in a table to detect an upward shift or a downward shift in process quality (one-sided Cusum) or in both directions (Two-sided Cusum).

\section{Designing of Cusum Scheme for Accident Fatality}

The Cusum chart is often used to detect an upward or downward shift in the process quality (one-sided Cusum chart) or shift in both directions (Two-sided Cusum Chart). To monitor a positive shift from the target value, the Cusum statistic is given as:

$$
C_{i}=\max \left[0,\left\{X_{i}-k\right\}+C_{i-1}\right]
$$

For monitoring upward movement and for monitoring downward movement, the statistic is

$$
C_{i}^{*}=\min \left[0,\left\{X_{i}-k\right\}+C_{i-1}^{*}\right]
$$

The process is taken to be out-of-control if $C_{i}>h$ for an upward shift or $C_{i}^{*}<-h$ for a downward shift. The procedures for determination of the parameters of the Cusum chart ( $K$ and $h$ ) as discussed in the literatures (see $[3,4])$ are presented below.

For a counted data Cusum, the parameters to be determined are the reference value $(k)$ and the decision interval $(h)$ The value $k$ can be described as the reference value for the process; which is usually chosen between the acceptable process mean value $\left(\mu_{0}\right)$ and the mean level that the Cusum scheme is inherited to detect quickly $\left(\mu_{1}\right)$, otherwise known as the rejectable mean value. The values of $\mu_{0}$ and $\mu_{1}$ are mean numbers of counts per sampling interval. The reference value $k$ for the counted Cusum should be chosen close to

$$
k=\frac{m_{1}-m_{0}}{\ell n m_{1}-\ell n m_{0}}
$$

The decision interval, $h$, is determined by specifying the in-Control (IC) and out-of-Control (OC) average run length (ARL). The IC-ARL is the average number of consecutive procedures required for a Cusum chart to cross a decision interval or signal during the period when the process is performing at an acceptable level. This is analogous to Type I error or false-positive error in hypothesis testing. On the other hand, the OC-ARL is the average number of procedures performed before the Cusum chart signals, during the period when the process is performing at an unacceptable level. It is a measure of sensitivity and is analogous to power, Type II error or false-negative error in hypothesis testing.

A design with short IC-ARL (large type I error) is prone to false alarm while a design with short OC-ARL (high power) will quickly detect poor performance. Ideally, Cusum monitoring requires long IC-ARL (small type I error) and short OC-ARL (high power) before the chart signals an actual deterioration in performance. Unfortunately, thus ideal could not be reached, as a desirably long IC-ARL (small type I error) will lead to unacceptably long OC-ARL (low power). On the other hand, the desired short OC-ARL (high power) will lead to more frequent false alarm of short IC-ARL (large type I error). Hence, a trade-off is made between them. For normally 
distributed random variables, Ewan \& Kemp [11] determined the ARL at $\mu_{0}$ (call it $L_{0}$ ) and the ARL at $\mu_{1}$ (call it $L_{1}$ ). These ARLs are functions of $h$,

$$
\left|k-\mu_{0}\right|=\left|k-\mu_{1}\right| \text { and } \frac{\sigma}{n} \text {. Thus, when the reference }
$$

value, $k$ is obtained using Equation (2.5) the corresponding decision interval, $h$ is obtained using the nomograph table (see [5]) or the tables of $C_{1}$ and $C_{2}$ schemes for Poisson variable as presented in British Standard 5703, part 4 [12].

The data used in this work was obtained from the Department of Policy, Research and Statistics of the Federal Road Safety Corps (FRSC), Ondo State Command, Akure, Nigeria for the period January 2001 to December 2010. Thus it covers the period of 120 months. The data is on road accident fatalities that occurred within the State for the period under consideration as recorded on the spot of the road accidents.

The global expectation on road accident fatalities is to reduce or minimize the occurrence of death from road accidents. Therefore, a downward trend in the CUSUM path will reflect the expectation of the globe. However, a plot of the Cusum value of the recorded road accident fatalities reflected an upward movement as shown in Figure 1. Hence, we design a Cusum chart for an upward shift. This will enable us to monitor the upward trend and locate the point at which an unbearable number of occurrences are likely to happen.

From the data for the 120 months, the overall mean per month is $\bar{X}=9$ and the standard deviation $\sigma=8.2$. Thus, in other to detect changes in the mean level of road fatalities during this period, the acceptable mean level is chosen nearer to the current mean level, i.e. $\mu_{0}=9$ and standard deviation $\sigma=8.2$. Suppose the authority demands a shift of $1.5 \sigma$ from $\mu_{0}$ to be the rejectable level, then a shift of $1.5 \sigma$ in the positive direction yields $\mu_{1}=21$. Using Equation (2.4), the reference value $k$ is computed. Thus,

$$
k=\frac{21-9}{\ln (21)-\ln (9)} \approx 12
$$

To obtain the decision interval, $h$, the corresponding value of $h$ from table $C_{2}$ of BS 5703, Part 4, when $k=12$, is equal to 11 . Thus, the parameters of the designed Cusum are $k=12$ and $h=11$. Therefore, an out-of-control signal will be indicated when

$C_{i}=\max \left[0, X_{i}-12+C_{i-1}\right]>11$. The plot of the Cusum values with the obtained decision interval, $h$ is plotted in Figure 1.

From Figure 1, it is observed from the Cusum chart that the Cusum values for the first 71 months are less than the decision interval $(h)$. From the $72^{\text {nd }}$ to the $89^{\text {th }}$ months, an upward movement was observed. Thereafter from the $90^{\text {th }}$ to the $108^{\text {th }}$ months a slight downward shift in the Cusum values were observed. The last segment of the Cusum control chart reflect an upward movement. It should be noted that from the $72^{\text {nd }}$ month to the $120^{\text {th }}$ month, the Cusum values were above the decision interval. Thus, the process of the monthly road accident fatalities can be adjudged to be out-of-control. An important feature of the Cusum Control chart is reflected in Figure 1, the point of change is clearly visible.

In order to know the exact time of the year when the road accident fatality is more prominent, the data were broken down into yearly basis and the corresponding Cusum statistic for each year are implemented to detect increase in road accident occurrence as shown in Tables 1-10.

\section{Discussion of Results}

The design Cusum with reference value $k=12$ and decision interval, $h=11$ for the period of one hundred and twenty (120) months as plotted in Figure 1 reflect that the period under consideration can be categorized into three segments. The first segment is the period 2001 to November, 2006 where the road accident fatalities were less than the decision interval. This implies that, though

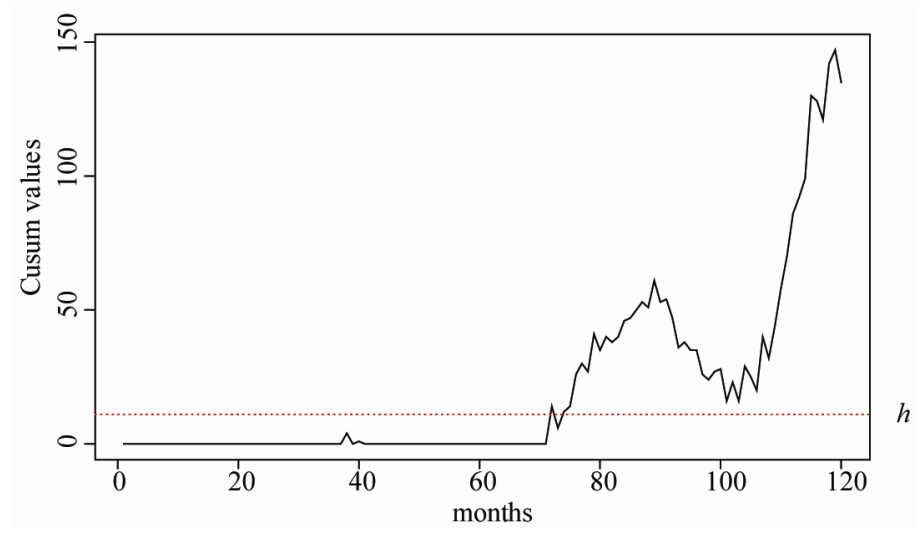

Figure 1. Cusum control chart for road accident fatalities. 
Table 1. Cusum tabulation for road accident fatality for year 2001.

\begin{tabular}{ccccc}
\hline & $X_{i}$ & $X_{i}-k$ & $\sum\left(X_{i}-k\right)$ & $C_{i}$ \\
\hline Jan & 5 & -7 & -7 & 0 \\
Feb & 0 & -12 & -19 & 0 \\
Mar & 6 & -6 & -25 & 0 \\
Apr & 8 & -4 & -29 & 0 \\
May & 4 & -8 & -37 & 0 \\
Jun & 0 & -12 & -49 & 0 \\
Jul & 3 & -9 & -58 & 0 \\
Aug & 7 & -5 & -63 & 0 \\
Sept & 2 & -10 & -73 & 0 \\
Oct & 3 & -9 & -82 & 0 \\
Nov & 4 & -8 & -90 & 0 \\
Dec & 9 & -3 & -93 & 0 \\
\hline
\end{tabular}

Table 2. Cusum tabulation for road accident fatality for year 2002.

\begin{tabular}{ccccc}
\hline & $X_{i}$ & $X_{i}-k$ & $\sum\left(X_{i}-k\right)$ & $C_{i}$ \\
\hline Jan & 3 & -9 & -9 & 0 \\
Feb & 2 & -10 & -19 & 0 \\
Mar & 4 & -8 & -27 & 0 \\
Apr & 6 & -6 & -33 & 0 \\
May & 0 & -12 & -45 & 0 \\
Jun & 7 & -5 & -50 & 0 \\
Jul & 3 & -9 & -59 & 0 \\
Aug & 3 & -9 & -68 & 0 \\
Sept & 5 & -7 & -75 & 0 \\
Oct & 2 & -10 & -85 & 0 \\
Nov & 8 & -4 & -89 & 0 \\
Dec & 6 & -6 & -95 & 0 \\
\hline
\end{tabular}

Table 3. Cusum tabulation for road accident fatality for year 2003.

\begin{tabular}{ccccc}
\hline & $X_{i}$ & $X_{i}-k$ & $\sum\left(X_{i}-k\right)$ & $C_{i}$ \\
\hline Jan & 7 & -5 & -5 & 0 \\
Feb & 0 & -12 & -17 & 0 \\
Mar & 0 & -12 & -29 & 0 \\
Apr & 3 & -9 & -38 & 0 \\
May & 6 & -6 & -44 & 0 \\
Jun & 4 & -8 & -52 & 0 \\
Jul & 5 & -7 & -59 & 0 \\
Aug & 6 & -6 & -65 & 0 \\
Sept & 0 & -12 & -77 & 0 \\
Oct & 7 & -5 & -82 & 0 \\
Nov & 3 & -9 & -91 & 0 \\
Dec & 10 & -2 & -93 & 0 \\
\hline
\end{tabular}

Table 4. Cusum tabulation for road accident fatality for year 2004.

\begin{tabular}{ccccc}
\hline & $X_{i}$ & $X_{i}-k$ & $\sum\left(X_{i}-k\right)$ & $C_{i}$ \\
\hline Jan & 11 & -1 & -1 & 0 \\
Feb & 16 & 4 & 3 & 4 \\
Mar & 0 & -12 & -9 & 0 \\
Apr & 13 & 1 & -10 & 1 \\
May & 2 & -10 & -20 & 0 \\
Jun & 9 & -3 & -23 & 0 \\
Jul & 8 & -4 & -27 & 0 \\
Aug & 5 & -7 & -34 & 0 \\
Sept & 4 & -8 & -42 & 0 \\
Oct & 9 & -3 & -45 & 0 \\
Nov & 7 & -5 & -50 & 0 \\
Dec & 4 & -8 & -58 & 0 \\
\hline
\end{tabular}

Table 5. Cusum tabulation for road accident fatality for year 2005.

\begin{tabular}{ccccc}
\hline & $X_{i}$ & $X_{i}-k$ & $\sum\left(X_{i}-k\right)$ & $C_{i}$ \\
\hline Jan & 6 & -6 & -6 & 0 \\
Feb & 2 & -10 & -16 & 0 \\
Mar & 8 & -4 & -20 & 0 \\
Apr & 4 & -8 & -28 & 0 \\
May & 7 & -5 & -33 & 0 \\
Jun & 3 & -9 & -42 & 0 \\
Jul & 5 & -7 & -49 & 0 \\
Aug & 0 & -12 & -61 & 0 \\
Sept & 6 & -6 & -67 & 0 \\
Oct & 3 & -9 & -76 & 0 \\
Nov & 9 & -3 & -79 & 0 \\
Dec & 11 & -1 & -80 & 0 \\
\hline
\end{tabular}

Table 6. Cusum tabulation for road accident fatality for year 2006.

\begin{tabular}{ccccc}
\hline & $X_{i}$ & $X_{i}-k$ & $\sum\left(X_{i}-k\right)$ & $C_{i}$ \\
\hline Jan & 4 & -8 & -8 & 0 \\
Feb & 0 & -12 & -20 & 0 \\
Mar & 2 & -10 & -30 & 0 \\
Apr & 2 & -10 & -40 & 0 \\
May & 11 & -1 & -41 & 0 \\
Jun & 6 & -6 & -47 & 0 \\
Jul & 2 & -10 & -57 & 0 \\
Aug & 0 & -12 & -69 & 0 \\
Sept & 8 & -4 & -73 & 0 \\
Oct & 10 & -2 & -75 & 0 \\
Nov & 0 & -12 & -87 & 0 \\
Dec & 26 & 14 & -73 & $14^{*}$ \\
\hline
\end{tabular}


Table 7. Cusum Tabulation for road accident fatality for year 2007.

\begin{tabular}{ccccc}
\hline & $X_{i}$ & $X_{i}-k$ & $\sum\left(X_{i}-k\right)$ & $C_{i}$ \\
\hline Jan & 4 & -8 & -8 & 0 \\
Feb & 18 & 6 & -2 & 0 \\
Mar & 14 & 2 & 0 & 0 \\
Apr & 24 & 12 & 12 & $12^{*}$ \\
May & 16 & 4 & 16 & $16^{*}$ \\
Jun & 9 & -3 & 13 & $13^{*}$ \\
Jul & 26 & 14 & 27 & $27^{*}$ \\
Aug & 6 & -6 & 21 & $21^{*}$ \\
Sept & 17 & 5 & 26 & $26^{*}$ \\
Oct & 10 & -2 & 24 & $24^{*}$ \\
Nov & 14 & 2 & 26 & $26^{*}$ \\
Dec & 18 & 6 & 32 & $32^{*}$ \\
\hline
\end{tabular}

Table 8. Cusum tabulation for road accident fatality for year 2008.

\begin{tabular}{ccccc}
\hline & $X_{i}$ & $X_{i}-k$ & $\sum\left(X_{i}-k\right)$ & $C_{i}$ \\
\hline Jan & 13 & 1 & 1 & 1 \\
Feb & 15 & 3 & 4 & 4 \\
Mar & 15 & 3 & 7 & 7 \\
Apr & 20 & 8 & 15 & $15^{*}$ \\
May & 12 & 0 & 15 & $15^{*}$ \\
Jun & 4 & -8 & 7 & 7 \\
Jul & 13 & 1 & 8 & 8 \\
Aug & 5 & -7 & 1 & 1 \\
Sept & 1 & -11 & -10 & 0 \\
Oct & 14 & 2 & -8 & 0 \\
Nov & 9 & -3 & -11 & 0 \\
Dec & 12 & 0 & -11 & 0 \\
\hline
\end{tabular}

fatalities exist within the said period but the rate is not alarming. In the second and third segment, the Cusum values were outside the decision interval. This implies an upward shift in the process. The cumulative sum of the fatalities increases from December, 2006 to May, 2008, thereafter a downward shift was observed from June 2008 to December, 2009. It should be noted that the downward shift is not an improvement or reduction per se, since the values at this period were still far above the decision interval. The Cusum tabulation in Table 1 through Table 10 shows that the road accident fatalities during the period January 2001 to November 2007 (see Tables 1-6) were close and no alarming rate of occurrence was observed. For the periods where alarming rate was displayed, it is very easy to detect the period of the year when the highest occurrence of road accident fatalities
Table 9. Cusum tabulation for road accident fatality for year 2009.

\begin{tabular}{ccccc}
\hline & $X_{i}$ & $X_{i}-k$ & $\sum\left(X_{i}-k\right)$ & $C_{i}$ \\
\hline Jan & 24 & 12 & 12 & $12^{*}$ \\
Feb & 26 & 14 & 26 & $26^{*}$ \\
Mar & 24 & 12 & 38 & $38^{*}$ \\
Apr & 28 & 16 & 54 & $54^{*}$ \\
May & 20 & 8 & 62 & $62^{*}$ \\
Jun & 19 & 7 & 69 & $69^{*}$ \\
Jul & 43 & 31 & 100 & $100^{*}$ \\
Aug & 10 & -2 & 98 & $98^{*}$ \\
Sept & 5 & -7 & 91 & $91^{*}$ \\
Oct & 33 & 21 & 112 & $112^{*}$ \\
Nov & 17 & 5 & 117 & $117^{*}$ \\
Dec & 0 & -12 & 105 & $105^{*}$ \\
\hline
\end{tabular}

Table 10. Cusum Tabulation for road accident fatality for year 2010.

\begin{tabular}{ccccc}
\hline & $X_{i}$ & $X_{i}-k$ & $\sum\left(X_{i}-k\right)$ & $C_{i}$ \\
\hline Jan & 24 & 12 & 12 & $12^{*}$ \\
Feb & 26 & 14 & 26 & $26^{*}$ \\
Mar & 24 & 12 & 38 & $38^{*}$ \\
Apr & 28 & 16 & 54 & $54^{*}$ \\
May & 20 & 8 & 62 & $62^{*}$ \\
Jun & 19 & 7 & 69 & $69^{*}$ \\
Jul & 43 & 31 & 100 & $100^{*}$ \\
Aug & 10 & -2 & 98 & $98^{*}$ \\
Sept & 5 & -7 & 91 & $91^{*}$ \\
Oct & 33 & 21 & 112 & $112^{*}$ \\
Nov & 17 & 5 & 117 & $117^{*}$ \\
Dec & 0 & -12 & 105 & $105^{*}$ \\
\hline
\end{tabular}

occurred. From Table 6, December 2006 was the only month that has a Cusum value that is more than the decision interval. For year 2007 (Table 7), December also has the highest Cusum value. In year 2008 (see Table 8), the highest Cusum values was in April and May. From Tables 9 and $\mathbf{1 0}$ the highest occurrence is in the month of November. It should be noted that the months where the highest occurrence of road accident fatalities were observed for the years are all festive periods such as Christmas, Easter, Eid-el-Kabir, and Eid-el-Moluod.

\section{Conclusion}

The Cusum chart plotted for road accident fatality data is capable of detecting small shift from the mean level. More so, the points of change in the process are clearly identified and points at which these occurred are easily 
located on the CUSUM in Figure 1. Thus, CUSUM chart provides visual aids diagnosis and identifies the situations that require quick attention. The months where high occurrence of road accident fatalities are identified should be used as benchmark by road manager especially Federal Road safety Corps (FRSC) as periods where more attention or precaution measure should be put in place on the roads to drastically reduce or eliminate high occurrence of road accident fatalities. The design Cusum control chart can be adapted for other states in the country, the entire country and for other countries of the world.

\section{REFERENCES}

[1] World Health Organization, “The Health Report-Global Burden of Diseases,” 2008.

[2] Y. Zhao, F. Tsung and Z. J. Wang, "Dual CUSUM Control Schemes for a Mean Range Detection CUSUM," IIE Transactions, Vol. 37, No. 11, 2005, pp. 1047-1057. doi:10.1080/07408170500232321

[3] E. S. Page, “Continuous Inspection Schemes," Biometrika, Vol. 41, No. 1-2, 1954, pp.100-114. doi:10.1093/biomet/41.1-2.100

[4] J. M. Lucas, “Counted Data CUSUM's," Technometrics, Vol. 27, No. 2, 1985, pp. 199-244.
[5] E. R. Ott, E. G. Schilling and D. V. Neubauer, "Process Control: Trouble Shooting and Interpretation of Data," 4th Edition, Quality Press, Milwaukee, 2005.

[6] D. C. Montgomery, "Introduction to Statistical Quality Control,” 4th Edition, John Wiley and Sons, New York, 2005.

[7] P. A. Osanaiye and C. O. Talabi, "On Some Non-Manufacturing Application of Counted Data Cumulative Sum (Cusum) Control Chart Scheme," The Statistician, Vol. 38, 1989, pp. 251-257. doi:10.2307/2349058

[8] K. S. Adekeye, "Use of Cumulative Sum Control Chart for Detection of Increase in Crime Rate,” Nigerian Journal of Mathematics and Application, Vol. 15, 2002, pp. 188-196.

[9] A. B. Nix, R. J. Rowlands and K. W. Kemp, "Internal Quality Control,” Clinical Medicine, Vol. 6, 1986, pp. 425-440.

[10] W. S. W. Lin and B. M. Adams, "Combined Control Chart for Forecast-Based Monitoring Schemes," Journal of Quality Technology, Vol. 28, No. 3, 1996, pp. 289-301.

[11] K. W. Kemp, "The Use of Cumulative Sum for Sampling Inspection Schemes,” Applied Statistics, Vol. 11, No. 1, 1962, pp. 16-31. doi:10.2307/2985287

[12] British Standards Institution, "British Standards Guide to Data Analysis and Quality Control Using CUSUM Techniques, Part 4,” 1982. 